\title{
A resolução de conflitos e a educação para a paz
}

\author{
La resolución de conflictos y la educación para la paz \\ Conflict Resolution and Education for Peace
}

\author{
Lis Rejane Martins Rolan ${ }^{1}$ \\ Lúcio Jorge Hammes ${ }^{2}$ \\ Itamar Luís Hammes ${ }^{3}$
}

\begin{abstract}
Resumo
A publicação da lei $n^{\circ} 13.663$ que altera o artigo 12 da Lei de Diretrizes e Bases da educação para incluir a promoção de medidas de conscientização, de prevenção e de combate a todos os tipos de violência e a promoção da cultura de paz entre as incumbências no âmbito das escolas. O objetivo do artigo é analisar a incidência da violência entre professor e aluno e entre os alunos dos anos finais do Ensino Fundamental de uma escola de Santa Vitória do Palmar do Rio Grande do Sul. Os dados foram coletados através da análise dos documentos da escola e através de questionário feito com professores deste educandário. Estes dados foram analisados quantitativa e qualitativamente para evidenciar estes conflitos em busca de acordos e a sua resolução não violenta, tendo por base os estudos atuais da ciência da paz. Os resultados indicam a necessidade de aprofundamentos sobre a temática, organizando encontros de estudos, oficinas e palestras e a pesquisa de uma intervenção pedagógica a ser desenvolvida com os professores desta escola.
\end{abstract}

Palavras-chaves: resolução de conflitos; educação infantil; cultura da paz

\section{Resumen}

La publicación de la ley n 13.663 que modifica el artículo 12 de la Ley de Directrices y Bases de la educación para incluir la promoción de medidas de concientización, prevención y combate a todos los tipos de violencia y la promoción de la cultura de paz entre las tareas ámbito de las escuelas. El objetivo del artículo es analizar la incidencia de la violencia entre profesor y alumno y entre los alumnos de los años finales de la Enseñanza Fundamental de una escuela de Santa Vitória del Palmar de Rio Grande do Sul. Los datos fueron recolectados a través del análisis de los documentos de la escuela y, a través de un cuestionario hecho con profesores de este educandario. Estos datos fueron analizados cuantitativa y cualitativamente para evidenciar estos conflictos en busca de acuerdos y su resolución no violenta, tomando como base los estudios actuales de la ciencia de la paz. Los resultados indican la necesidad de profundizaciones sobre la temática, organizando encuentros de estudios, talleres y charlas y la investigación de una intervención pedagógica a ser desarrollada con los profesores de esta escuela.

Palabras claves: resolución de conflictos; Combate a violencia; cultura de la paz

\begin{abstract}
The publication of Law No. 13,663, which amends article 12 of the Law on Guidelines and Bases of Education, to include the promotion of measures to raise awareness, prevent and combat all types of violence and promote a culture of peace in the school. The objective of the article is to analyze the incidence of violence between teacher and student and between the students of the final years of Elementary School of a school in Santa Vitória do

\footnotetext{
1 Mestranda em Educação -Universidade Federal do Pampa (UNIPAMPA). Jaguarão/RS (Brasil). E-mail: lisrejanerolan@gmail.com.

${ }^{2}$ Doutor em educação. Professor da Universidade Federal do Pampa (UNIPAMPA). Jaguarão/RS (Brasil); Email: luciojh@gmail.com.

${ }^{3}$ Doutor em Filosofia; Instituto Federal de Educação, Ciência e Tecnologia Sul-rio-grandense - IFSUL; Lajeado, RS, Brasil; itamarh57@gmail.com.
} 
Palmar from Rio Grande do Sul. Data were collected through the analysis of school documents and through a questionnaire made with teachers of this school. These data were analyzed quantitatively and qualitatively to evidence these conflicts in search of agreements and their non-violent resolution, based on the current studies of the science of peace. The results indicate the need for further study on the subject, organizing study meetings, workshops and lectures and the research of a pedagogical intervention to be developed with the teachers of this school.

Keywords: conflictresolution; Fightagainstviolence; culture of peace

\section{Introdução}

Umas das maiores adversidades que as escolas enfrentam na contemporaneidade é a violência escolar, resultado de conflitos mal resolvidos. Sabe-se que em diversas situações, as ações para superar esta violência não resultam na eficácia desejada. Constatam-se conflitos entre os professores, entre os alunos e professores, entre os alunos e alunos, entre professores e direção. Mas, especialmente os conflitos entre os alunos e os professores podem trazer consequências que prejudicam o aprendizado e podem desestabilizar o ambiente escolar.

Já sabemos que conflitos existem onde as pessoas se encontram, em todas as relações humanas e em qualquer lugar, portanto faz parte do ser humano. Depende de nós, para que estes conflitos não levem a ações de violência, e da sua resolução podendo, inclusive, ser base para a construção de relações de cooperação e que levem à vivência da paz.

Depende, portanto da forma como o conflito é resolvido e assim formar pessoas que possam conviver em paz e relacionar-se bem em sociedade, baseada em valores afetivos, morais e éticos para o desenvolvimento da educação de qualidade.

Um desafio para a educação é buscar maneiras para a resolução dos conflitos que não levem à violência e que possam contribuir para o desenvolvimento de uma educação para a paz, tornando o ambiente escolar um ambiente de boa convivência, propício para que alunos e professores possam buscar aprendizagens importantes para o desenvolvimento da cidadania.

Este artigo é resultado de uma pesquisa bibliográfica que busca investigar os principais motivos dos conflitos existentes na Escola Municipal de Ensino Fundamental Aresmi Tavares Rodrigues em Santa Vitória do Palmar, do Rio Grande do Sul, nos anos finais do Ensino Fundamental dos nove anos. O conhecimento dos motivos relacionados aos conflitos pode ser base importante para a sua resolução, tornando estes conflitos um potencial para a educação para a paz e a construção de uma cultura de paz.

\section{Metodologia do trabalho}

Os instrumentos procedimentos metodológicos utilizados nessa pesquisa foram coleta de dados em documentos na escola, questionário aplicado para os professores das disciplinas 
ministradas nas séries finais do ensino fundamental para uma investigação sobre o assunto. $\mathrm{O}$ estudo teve uma abordagem qualitativa intervencionista a partir de círculos de aprendizagem numa perspectiva freireana, propiciando a criação de um espaço onde prevaleceu a fala e a escuta qualificada.

O estudo baseou-se no desenvolvimento da metodologia dos círculos de aprendizagem com os profissionais que se propuseram fazer parte do aprofundamento de estudos, reflexões e discussões sobre o tema em questão que é a resolução de conflitos na Educação. Foram sugeridos e aceitos 04 círculos de aprendizagem presencial e organização de debates com as turmas onde os sujeitos da pesquisa fazem parte. Certamente será uma oportunidade interessante para escutar e dialogar com os profissionais que atuam na escola.

Para fins de intervenção, a escolha dos círculos de aprendizagem se deu por proporcionarem momentos de diálogo e discussões responsáveis, indo ao encontro a proposta freireana, de formação colaborativa e da busca coletiva por novos conhecimentos que refletirão nas relações pessoais de cada sujeito. O grupo de estudo foi constituído por 05 professores que atuam nas séries finais do ensino fundamental do $6^{\circ}$ ao $9^{\circ}$ ano da escola; 01 estagiário do CIEE, 03 atendentes e 05membros da equipe diretiva, os alunos das séries finais, totalizando 94 sujeitos de pesquisa.

A proposta dos círculos de aprendizagem é compreendida melhor se a relacionarmos com os círculos de cultura de Freire, definindo que: "Estes círculos encontram sua referência básica no diálogo, entendido como um elemento essencial no processo educativo, e respondem à exigência radical das pessoas que não podem se construir fora da comunicação" (HAMMES et al, 2017 p.104). Neste sentido os círculos de aprendizagem, no contexto desta pesquisa, foram envolvidos professores efetivos, atendentes efetivos, estagiário ligado ao CIEE em comunhão e na busca do conhecimento, repensando a educação. Os profissionais foram selecionados conforme disponibilidade e interesse na busca e produção de novos conhecimentos.

\section{Combate a todo tipo de violência}

A Lei $\mathrm{n}^{\circ}$ 13.663, de 14 de maio de 2018altera o art. 12 da Lei $\mathrm{n}^{\circ}$ 9.394, de 20 de dezembro de 1996, para incluir a promoção de medidas de conscientização, de prevenção e de combate a todos os tipos de violência e a promoção da cultura de paz entre as incumbências dos estabelecimentos de ensino. 
Art. $1^{\circ} \mathrm{O}$ caput do art. 12 da Lei $\mathrm{n}^{\circ}$ 9.394, de 20 de dezembro de 1996, passa a vigorar acrescido dos seguintes incisos IX e X:

IX - promover medidas de conscientização, de prevenção e de combate a todos os tipos de violência, especialmente a intimidação sistemática (bullying), no âmbito das escolas;

$\mathrm{X}$ - estabelecer ações destinadas a promover a cultura de paz nas escolas.

A promoção da cultura da paz é uma ação que deverá ser posta em prática nas escolas e demais locais de formadores de opinião para que haja compreensão da necessidade urgente de se estabelecer uma educação para a paz propondo medidas para que a paz seja implantada nos educandários brasileiros.

\begin{abstract}
A educação para a paz tem-se tornado ponto de políticas públicas - locais, nacionais e internacionais -, passando a ser incluída em convênios, recomendações e declarações, sendo fortemente recomendada pela ONU e UNESCO. Em 1999, pacifistas do mundo inteiro, reunidos para celebrar o centenário da famosa conferência de Haia pela paz, chegaram à conclusão de que seus esforços teriam sentido apenas com a garantia de oferecer às futuras gerações uma educação que, ao invés de glorificar a guerra, contribuísse para a promoção dos direitos humanos e da compreensão internacional. Assim, na firme convicção de que não haverá paz sem educação para a paz, lançaram uma campanha mundial de educação paraa paz, com o duplo objetivo de conquistar reconhecimento público da significação e importância de tal educação e de capacitar professores para realizarem tal tarefa. (GUIMARÃES, 2006. p.330).
\end{abstract}

Diante dessa nova Lei, há a necessidade de organizar o ambiente escolar comações que visem uma conscientização de se ter um bom relacionamento com as pessoas que convivemos. O ambiente escolar necessita ser um local agradável, seguro, com clima de amizade, de consideração para que se possa querer participar das atividades propostas com alegria, entusiasmo e responsabilidade; fazendo sempre o melhor para assegurar um desenvolvimento pessoal e de grupo buscando aprendizagens em cada momento vivido, que é único.

A prevenção da violência acredita-se que é um caminho a ser percorrido, pois a partir daí há possibilidades de serem feitas abordagens e ações de conscientização sendo necessário que haja uma qualificação dos professores para serem mediadores de conflitos nas escolas, pois estão sempre em contato com os alunos. O conflito pode acontecer entre aluno e professor, entre pais e professores, entre aluno e aluno ou entre comunidade e escolar. Diante disso, procura-se saber o porquê desses conflitos dentro do espaço escolar e assim buscar tentativas de solucioná-los com a participação de todos, para juntos buscar possibilidades de entendimento. Ao acontecer fatos, que às vezes possam parecer irrelevantes, deve-se tomar a iniciativa de propor uma conversa com os envolvidos para esclarecimento do motivo que levou ao fato. Diante disso, orientar os alunos, que não há necessidades de se chegar as vias 
de fato para resolver situações de desavenças, pois com um diálogo e com acordos poderá ser resolvido o conflito e passar a ter uma convivência equilibrada.

Vê-se que atualmente o bullying está presente em muitas relações e que pode passar despercebido em sala de aula no intervalo, na entrada da escola, no transporte escolar, enfim em muitos lugares educativos. Para que ações sejam efetivadas na escola, precisa-se estar atento aos acontecimentos envolvendo discentes, docentes e demais pessoas envolvidas no ambiente escolar como exemplo: merendeiras, auxiliares, CIEEs, monitores que atuam no andamento das atividades escolares e lidam com todos os alunos da escola. Quanto à prática do bullying, muitos alunos acreditam que é apenas uma simples brincadeira, mas o discente que é perseguido pelos colegas sofre com essas atitudes inadequadas que podem ocorrer dentro e fora da escola. Eles comentam "é só uma brincadeira professora", quando é chamada a atenção por uma atitude inconveniente, não tendo consciência que está ferindo a outra pessoa com palavras ofensivas ou agressões físicas repetidas vezes perante os outros. Essas agressões, às vezes, pode ser um empurrão, um puxão de cabelo entre outros que parecem não serem graves, mas dependendo da situação e da forma como se dá esse mal-entendido poderá se tornar sério. Isso pode acontecer tanto na sala de aula quanto no intervalo, na merenda e em várias situações cotidianas. Muitas alunas e alunos dizem não se importar com essas atitudes dos colegas, mas percebe-se que não é bem assim. Praticar bullying é uma ação hostil e tem consciência de quanto é desrespeitoso quando se colocar no lugar do outro, percebendo assim como é desagradável passar por essa humilhação de poderá deixar marcas profundas.

A lei de proteção a quem sofre bullying institui o Programa de Combate à Intimidação Sistemática, Lei no 13.185 de 06 de Novembro de 2015 afirma:

Art. 1o Fica instituído o Programa de Combate à Intimidação Sistemática (Bullying) em todo o território nacional.

$\S 1$ o No contexto e para os fins desta Lei, considera-se intimidação sistemática (bullying) todo ato de violência física ou psicológica, intencional e repetitivo que ocorre sem motivação evidente, praticado por indivíduo ou grupo, contra uma ou mais pessoas, com o objetivo de intimidá-la ou agredi-la, causando dor e angústia à vítima, em uma relação de desequilíbrio de poder entre as partes envolvidas.

§ 2o O Programa instituído no caput poderá fundamentar as ações do Ministério da Educação e das Secretarias Estaduais e Municipais de Educação, bem como de outros órgãos, aos quais a matéria diz respeito.

Sabe-se que é uma tarefa árdua e é preciso ser persistente nas ações de combate a esse tipo de ofensa para que a cultura da paz seja possível ser construída e se estabeleça no convívio das pessoas. Somente com uma educação para a paz, poderá ser construída uma 
cultura de paz que passará a fazer parte da vida desse aluno e, portanto conseguir se relacionar bem dentro e fora da escola, na família, na sociedade.

\section{A Situação da escola}

A referida escola encontra-se num momento de reflexão diante do problema detectado. Baseada na análise da coleta de dados através de busca documental nas atas da escola, de observação de atitudes dos educandos e dos professores da escola diante da situação, foi verificado a incidência de brigas que acontecem nesse educandário. Percebe-se a necessidade de haver um diálogo em busca de resolução dos conflitos existentes, percebendo sua origem e solicitando sugestões aos envolvidos para que se chegue a um acordo com uma convivência pacífica e de respeito mútuo. O respeito é à base de todo relacionamento, através dele tem-se a compreensão com o outro ser. As pessoas que se fazem presentes na nossa convivência, seja na família, na escola ou na sociedade devem procurar manter um relacionamento sadio, dando espaço a diálogo a fim de solucionar atritos que estejam acontecendo nesses ambientes.

Para que haja a conscientização de uma educação para paz nas escolas, existe a necessidade de promover uma formação de professores para que saibam agir diante de conflitos com os alunos, pais e comunidade. Para Alicia Cabezudo:

Las habilidades psicosocialessonel componente central de este modelo de intervención, al ser una serie de destrezas indispensables para una relación armoniosa con otras personas, que enteoríadeberían ser enseñadas en lafamilia; sin embargo, esto no siempre es así. (CABEZUDO, 2010, p. 90)

Há uma preocupação com a maneira que o aluno é educado pela família, pois isso reflete diretamente na escola, contudo cabe à escola buscar a participação dos responsáveis pelos seus alunos em palestras orientadoras sobre como resolver esses desentendimentos, brigas, atritos, desarmonia nas relações com os outros, refletindo assim sobre o assunto achando uma maneira de mudança de comportamento para que haja uma melhora considerável e uma conciliação nos relacionamentos. 


\section{Gráfico 1 -Conflitos ocorridos na escola em 2017}

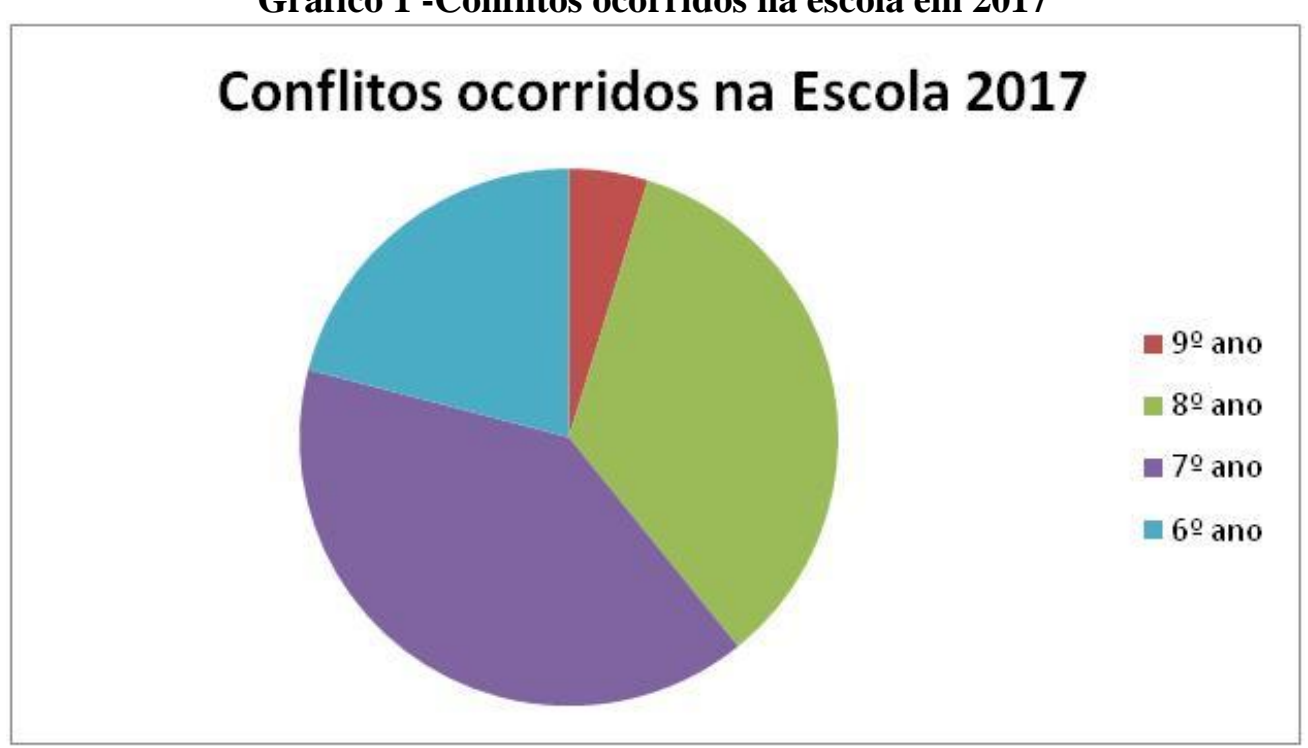

Fonte: Dados coletados para esta pesquisa

No ano de 2017 com um alto índice de violência, os educadores da escola têm uma grande preocupação com esse sentimento de impotência diante dos fatos, de saber como lidar com a situação conflitante. Foram registradas em atas, diversas situações que ocorreram na escola. Percebe-se que o índice mais alto ocorre no $7^{\circ}$ ano, e que no $9^{\circ}$ ano já há uma diminuição considerável de situações conflitantes.

Gráfico 2 -Conflitos ocorridos na escola em 2018

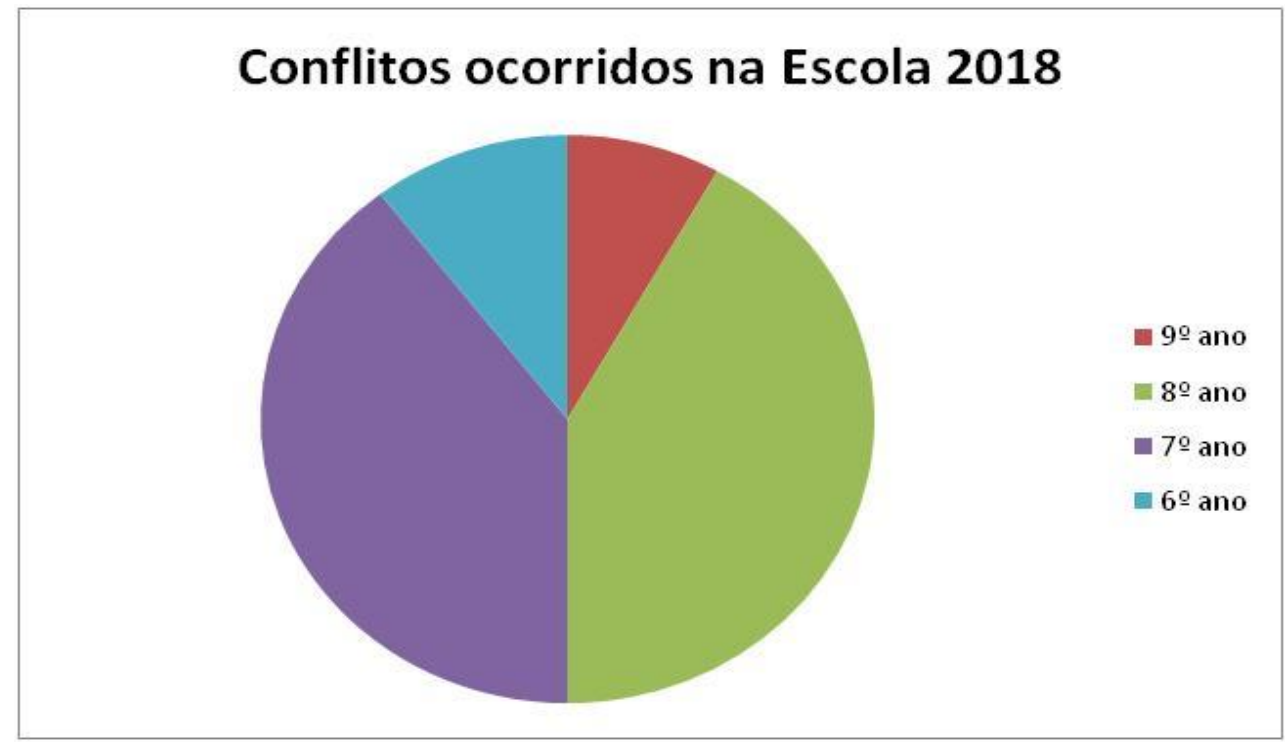

Fonte: Dados coletados para esta pesquisa

Embora no ano de 2018 tenha diminuído os conflitos na escola em questão, percebe-se que ainda é muito alto o índice de atitudes inadequadas que geram violência nesse 
educandário. Permanece alto o índice de atitudes preocupantes no $7^{\circ}$ ano e houve um aumento considerável no $8^{\circ}$ ano.

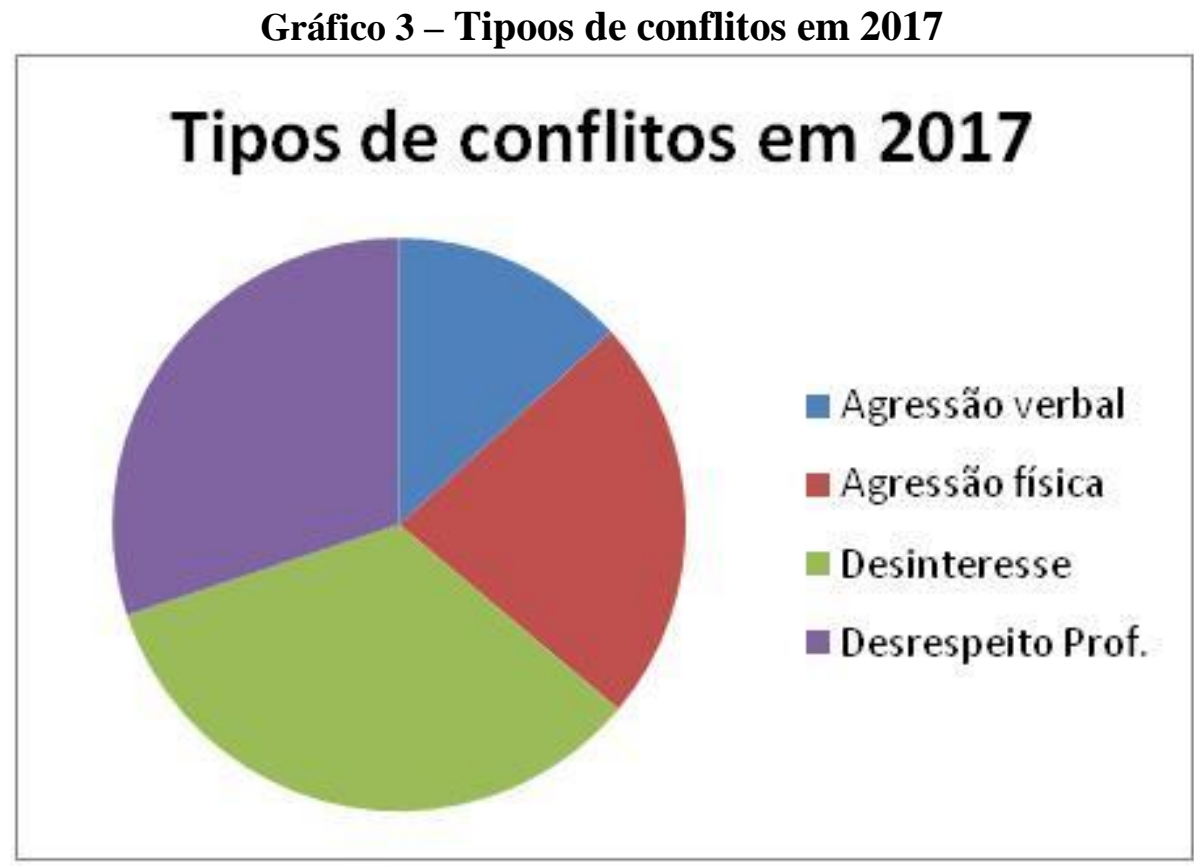

Fonte: Dados coletados para esta pesquisa

Observa-se que a agressão verbal e o desinteresse pelos estudos possui um alto índice no contexto escolar no ano de 2017. Esse desinteresse muitas vezes leva a repetência e trazendo assim mais desinteresse do aluno nos estudos, gerando assim brincadeiras, falta de estímulo de concretizar as tarefas solicitadas passando a perturbar a aula. Esse aluno precisa ser motivado e passar a interagir de forma dinâmica, para se sentir parte do contexto em que vive.

Gráfico 4 - Tipos de conflitos em 2018

\section{Tipos de conflitos em 2018}

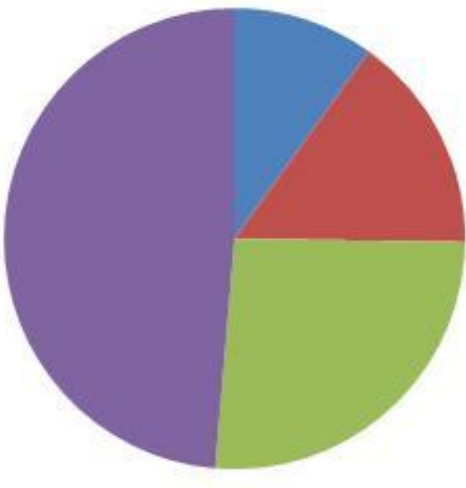

- Agressão verbal

- Agressão física

Desinteresse

Desrespeito Prof.

Fonte: Dados coletados para esta pesquisa 
No ano seguinte há um grande aumento de situações de desrespeito ao professor, ocasionando sérios problemas de relacionamento na escola. A agressão verbal e a agressão física entre aluno/aluno existente no ano de 2017 tiveram uma singela diminuição em 2018. Percebe-se que continuam a existir conflitos que geram esse tipo de atitude. $\mathrm{O}$ desinteresse diante dos estudos por parte dos alunos é outro fator inquietante, pois esses alunos não conseguem na grande maioria a aprovação nas avaliações, havendo um desestímulo ainda maior e quando vem essa reprovação fica ainda mais difícil esse educando querer estar na escola. Esse desinteresse ocasiona muita conversa aleatória em sala de aula, distração desconcentrando-se do assunto tratado na aula e passando assim a tumultuar com ações inapropriadas trazendo problemas de aprendizagem para si e para os demais.

Houve um aumento considerável de atas que registra a falta de respeito com o professor é muito sério e assustador, pois a desvalorização do profissional da educação é uma constante nas escolas públicas brasileiras.

No que tange aos questionários aplicados para os professores das séries finais das disciplinas existentes na escola, foram solicitados para 07 professores presentes que respondessem as cinco questões sobre o tema discutido. Foram devolvidos cinco documentos devidamente preenchidos, que nomearemos a partir de agora como professor A, B, C, D e E.

Referente à indagação se era de conhecimento dos professores, que fizeram parte dessa pesquisa, o conteúdo da Lei 13.663 de 2018, os professores A e D responderam que sim e os outros responderam que não. Foram questionados também se concordam que é possível trabalhar essa temática nas escolas, sendo que o professor A, D e E não responderam e o professor B e C disseram que sim.

Quanto ao questionamento sobre qual é a maior incidência dos conflitos existentes na escola, relataram que acreditam ser como segue descrito: Professores A e D acreditam que é a desmotivação escolar; os B e C acreditam que é o desrespeito aos professores na escola; o E acredita que é a agressão verbal.

Ao perguntar quais ações trariam resultados positivos em busca de soluções o professor A considera que deve ser trabalhado valores e regras e um trabalho realizado em equipe. O professor B acredita que a participação dos pais, palestras, aulas mais atrativas e curso de formação para docentes seriam ações importantes.O professor $\mathrm{C}$ pensa que a implantação de assembleia de turma seria uma ação importante para a formação cidadã dos alunos e sua criticidade. O professor D concorda com o professor B no item das aulas serem mais atrativas para os discentes e o uso da ludicidade em sala de aula. O professor E defende 
que deve haver uma mudança no pensamento da sociedade tendo a visão de que a educação leva o ser humano a ter um futuro melhor.

No que se refere à pergunta que trata de ações diretas do professor para contribuir na solução de conflitos o professor A considera que o diálogo com os alunos, o desenvolvimento da empatia com eles e mostrar que a assertividade deve fazer parte do cotidiano. O professor B discorre que o profissional tem que ser comprometido com a educação e sua atualização pedagógica, de conhecimentos entre outros devem ser constante. $\mathrm{O}$ professor $\mathrm{C}$ entende que os professores devem estar em constante contato com seus discentes, mediando os possíveis problemas que ocorrem. O professor D refere-se que ações como aulas motivadoras, oficinas, jogos, debates contribuiriam para a solução de conflitos. O Professor E entende que para que haja solução dos conflitos na escola a participação da família é fundamental.

Ao perguntar, no último questionamento feito, se gostaria de fazer parte como mediador de conflitos na escola os professores responderam como segue: O A não respondeu essa questão; o B e D responderam que sim, o C eE responderam que não gostariam.

\section{Considerações finais}

A educação para a paz e a resolução de conflitos nas escolas é um tema que deve ter uma atenção redobrada diante dos problemas enfrentados diariamente. Diante do alto índice de desrespeito com os professores, a criação de um grupo que organize ações efetivas, como por exemplo: palestras, discussões sistemáticas com grupos distintos abrangendo assim todos os envolvidos no contexto escolar. Promover a formação de professores e alunos mediadores de conflitos e posteriormente envolver educandos e comunidade escolar nessa ação para que se tenha uma melhora nas relações de convivência onde o respeito à pessoa, à amizade, à consideração pelo outro seja uma prática natural no dia-a-dia da escola.

Para Guimarães, 2006:

A ação comunitária traz uma nova dimensão para a compreensão kantiana da paz como acordo. A paz somente surgirá se a humanidade concordar em viver em paz. É preciso, então, operar um consenso humanitário para a paz, tal como acontece, por exemplo, com a Declaração Universal de Direitos Humanos. A humanidade não nasceu com esta noção e ela foi construídaatravés de um intenso e conflitivo processo social até estabelecer um consenso através dos documentos que foram sendo proclamados. Da mesma forma, a paz, como construção coletiva, não virá por decreto dos poderosos, nem mesmo virá apenas como consequência da audácia dos militantes pacifistas, mas será fruto do estabelecimento de um consenso discutido, conversado, negociado, entre as pessoas. (p. 336) 
Para que pessoas consigam se entender e conviver de maneira harmoniosa deverá haver sempre uma conversa, uma proposta de entendimento,de parceria, de ajuda ao próximo, de amor ao semelhante. A cultura da paz é construída em comum acordo com as pessoas envolvidas. Acredita-se que com a participação da comunidade escolar, dos professores, dos alunos, dos responsáveis por esses alunos, poderá se concretizar uma educação para a paz trazendo assim um grande benefício para todos.

Concluímos com Freire: “A escola será cada vez melhor, na medida em que cada ser se comportar como colega, como amigo, como irmão.” (RODRIGUES, 2016).

\section{Referência}

BRASIL. Presidência da República. Lei $n^{\circ}$ 13.185- Institui o Programa de Combate à Intimidação Sistemática (Bullying). Disponível em: https://www.jusbrasil.com.br/topicos/79645819/artigo-1-da-lei-n-13185-de-06-de-novembrode-2015. Acesso em Jan. 2019.

BRASIL. Presidência da República. Lei $n^{\circ} 13.663$ - Altera o art. 12 da Lei no 9.394. Disponível em: http://www.planalto.gov.br/ccivil_03/_ato2015-2018/2018/lei/L13663.htm. Acesso em mai. 2018.

CABEZUDO, Alícia. II. Educación para la paz. In: Gobierno del Distrito Federal. Escuelas Aprendiendo a Convivir: Un modelo de intervención contra el maltrato e intimidación entre escolares (bullying). México: Secretaría de Educación del Distrito Federal, 2010. Disponível em: https://www2.uned.es/intervencion-inclusion/documentos/Documentos\%20interes/ violencia5.pdf. Acesso em nov. 2018.

FREIRE, Paulo. Pedagogia da autonomia: saberes necessários à prática educativa. 25. ed. São Paulo: Cortez, 2002.

GADOTTI, Moacir etallii. Paulo Freire: uma bibliografia. São Paulo. Cortez, Instituto Paulo Freire, Brasília: UNESCO, 1996.

GUIMARÃES, Marcelo Rezende. A educação para a paz como exercício da ação comunicativa: alternativas para a sociedade e para a educação. Educação. Porto Alegre, ano XXIX, n. 2 (59), p. 329 - 368, Maio/Ago. 2006. Disponível em: http://revistaseletronicas.pucrs.br/ojs/index.php/faced/article/view/447. Acesso em mai. 2018.

RODRIGUES, José Paz. As aulas no cinema: Paulo Freire, o grande pedagogo do Brasil (cinco documentários sobre a sua vida e obra). 7 de setembro de 2016. Disponível em: http://pgl.gal/paulo-freire-grande-pedagogo-do-brasil-cinco-documentarios-vida-obra/.

Acessado em jan. 2019. 